\title{
Preventive Maintenance Decision Based on Data Envelopment Analysis and Technique for Order Preference by Similarity To ideal Solution
}

\author{
Fen Cheng ${ }^{1, a)}$ and Wanxin $\mathrm{Hu}^{1, b)}$ \\ ${ }^{1}$ Wuhan Railway Vocational College of Technology, Wuhan, 430205, China \\ a)841694205@qq.com \\ b) Corresponding author: hwx841694205@163.com
}

\begin{abstract}
In order to improve the effectiveness of multi-objective and multi-attribute decision of road preventive maintenance, the paper considers the characteristics of preventive maintenance decision-making, establishes a preventive maintenance decision-making model based on Data Envelopment Analysis (DEA) and technique for preference by similarity to ideal solution (TOPSIS). Using EDA to calculate the relative effectiveness of every decision index in preventive maintenance, and then calculate the relative effectiveness of the decision-making measures by using the method of multi-objective Euclidean distance. After that, the total order of the alternative results, and the best preventive maintenance decision of the road is finally achieved. The decision-making method takes the owner costs, user costs and construction period as input index, skid resistance, durability, water resistance, driving comfort, appearance, noise reduction as output index, the four kinds of alternative preventive maintenance measures are chosen. The results of case application showed that the model can effectively solve the multi-attribute decision-making problems of preventive maintenance.
\end{abstract}

Key words: Road engineering; DEA; TOPSIS; Preventive Maintenance Decision Conservation Measures

\section{INTRODUCTION}

Throughout the course of highway maintenance work, preventive maintenance, as a new technology, changed the original passive corrective conservation situation, which has been gradually applied in many provinces and cities in China. Preventive maintenance is intended to take reasonable measures before road structural diseases to extend the road service life, save maintenance funds. Preventive maintenance decision is a multi-object, multi-criteria and multi-attributes problem, many highway management departments in the United States have established preventive maintenance treatment selection decision tree (decision-making matrix), such as Ontario, Georgia, California and other. At present, quantitative analysis of preventive maintenance decision-making in China is still not mature, and the common method is still the combination of qualitative and quantitative methods. Each method has its advantages and disadvantages and the application scope. Therefore, the combination of two (or more) method has become one of the trend of the research on the maintenance decision. In view of the above 
research, this paper establishes a multi-objective multi-attribute preventive maintenance decision model based on DEA and TOPSIS for the purpose of reasonable selection of preventive maintenance measures to provide basis for the final preventive maintenance decision and guide decision-makers using reasonable preventive maintenance strategy.

\section{THE PROCESS OF COMBINED PREVENTIVE MAINTENANCE DECISION-MAKING MODEL}

\subsection{PREVENTIVE MAINTENANCE MEASURES}

To achieve the goal of effective preventive maintenance, it is necessary to carry out regular inspection, analysis and evaluation of pavement performance, and to investigate the disease types of each road section to determine whether the preventive maintenance is required or not. Secondly, according to the road grade, traffic volume, pavement damage degree, combined with the existing technical level of the management station, facilities and equipment conditions, the level of funding to filter out the need to use the preventive measures. Finally, according to the characteristics of the road disease, the social, economic, environmental, construction and other factors, to determine the best conservation measures, and to extend the service life of the road. Diagram of preventive maintenance decision-making process is shown in figure 1.

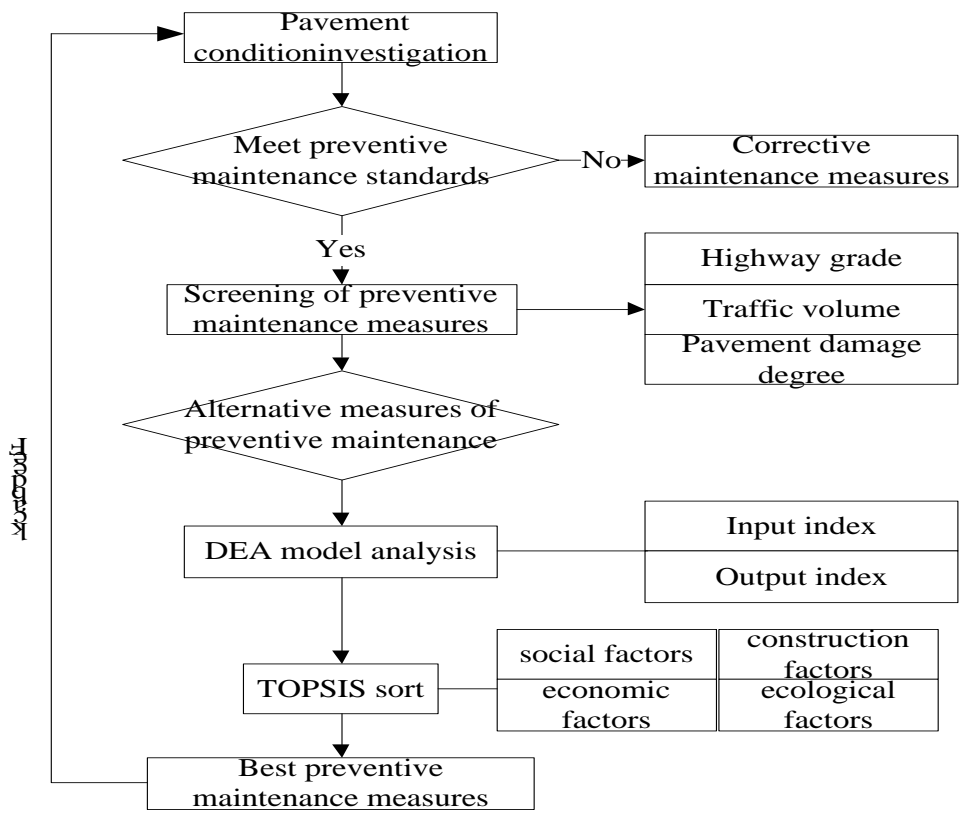

FIGURE 1 Process of preventive maintenance decision-making

\subsection{APPLICATION ANALYSIS OF DEA-TOPSIS}

DEA is evaluation method which is based on the concept of relative efficiency proposed by Charnes, is used to evaluate decision-making units with the same type of multiple inputs and multiple outputs (DMU). The method, evaluates the decision unit by the change weight is based on the input and output data. DEA method avoids determining the index weight, thus reducing the influence of subjective factors, so that the evaluation results are more objective. Preventive maintenance decision are affected by many factors, which is a multi-input, multi-output, multi- objective, multi-variability, and every decision will face different problems. Preventive conservation has a variety of measures, when choosing the specific measures, the comprehensive consideration of social, economic, environmental, construction and other factors, so as to select the most appropriate measures. 
In the classical DEA model, the specific index weight is selected according to its most favorable principle, and it may have many effective decisions, which cannot distinguish the difference between the decisions, that is, DEA effective decision-making unit cannot be sorted. TOPSIS was first proposed by Hwang and Yoon, Lai et applied the idea of TOPSIS to multi-objective decision making. TOPSIS can sort the ideal solution and the negative ideal solution of the decision making unit, decision unit solution that meet the requirements is near the ideal solution and away from the negative ideal solution, and so it can solve the distinction problem of decision units in DEA, and can be used to determine the synthetic index of the decision matrix.

\section{MODEL ANALYSES OF DEA/TOPSIS}

\subsection{DEA MODEL}

The basic principle of DEA method is to compare the relative efficiency of decision units by using the mathematical programming model after the input index, output index and the decision unit is determined, and then get the quantitative index value of the comprehensive efficiency of each decision unit.Through the comprehensive analysis of the input and output ratio, the comprehensive quantitative index value of each decision unit is obtained, and the relative efficiency value is 1 . The unit is DEA effective, relative efficiency value unit 1 is DEA effective decision-making unit.

DEA model has two forms, fractional programming and linear programming. These two forms are equivalent; in order to facilitate the calculation the paper uses the form of linear programming.

$$
\begin{aligned}
& \max \mu^{\mathrm{T}} y_{0}=h^{0} \\
& \left\{\begin{array}{l}
w^{T} x_{j}-\mu^{T} y_{j} \geq 0, j=1,2, \cdots, n \\
w^{T} x_{0}=1 \\
w \geq 0 \\
\mu \geq 0
\end{array}\right.
\end{aligned}
$$

In the above formula, $x_{j}=\left(x_{j 1}, x_{j 2}, \cdots, x_{j m}\right), y_{j}=\left(y_{j 1}, y_{j 2}, \cdots, y_{j 2}\right), u$ is the weight of $y_{j}$, $\mu=\left(\mu_{1}, \mu_{2}, \cdots, \mu_{s}\right)^{T}, w$ is the weight of $x_{j}, y_{0}=y_{j 0}, x_{0}=x_{j 0}$.An object that is used by decision making unit (DMU) or affected by DMU's production behavior is as the input, the product and benefit of the DMU is as the output. Usually the input index is also called the cost index, the smaller the better; the output index is called the benefit index, the bigger the better. But this is not absolute; the selection of input and output indicators should be based on the specific circumstances of the problem.

\subsection{TOPSIS MODEL}

The ideal solution is the best solution (denoted as $\mathrm{V}+$ ), which is the optimal value of each candidate solution, and the negative ideal solution is the worst solution (denoted as V-), which is the worst of all the candidates. Comparing preventive maintenance measures of the DMU which relative efficiency value is 1 , distance information is used as the Sorting criteria.

Because there may exist the situation that some preventive maintenance measures nearest to the $\mathrm{V}+$, but it is not the farthest to V-. Therefore, it is necessary to measure the proximity of the ideal solution, so as to further evaluate the pros and cons of the effective maintenance measures, and to produce the full ranking of all alternative preventive maintenance measures. The steps of the TOPSIS method are,

(1) Building the initial decision matrix. 
(2) Standardizing of the initial matrix. The number of alternative measures is $\mathrm{m}$, and the evaluation index is $n$, the initial decision matrix is $X=\left(x_{i j}\right)_{m \times n}$, normalized the input index (the smaller the better) and the output index (the bigger the better) respectively.

$$
\begin{aligned}
& \text { Input index } Z_{i j}=\left(1 / x_{i j}\right) / \sqrt{\sum_{i=1}^{m}\left(1 / x_{i j}\right)^{2}} \\
& \text { Output index } Z_{i j}=x_{i j} / \sqrt{\sum_{i=1}^{m}\left(x_{i j}\right)^{2}}
\end{aligned}
$$

(3) Establishing standardized decision matrix according to the weight of the identified weights. $W$ is the identified weight, $\mathrm{Z}$ is the standardized initial matrix, then the weighted standardized matrix is,

$$
V=\left(v_{i j}\right)_{m \times n}=\left(w_{j} \times Z_{i j}\right)_{m \times n}
$$

(4) Determining the positive and negative ideal solution,

$$
\left\{\begin{array}{l}
V^{+}=\left\{\left(\max V_{i j} \mid j \in J^{+}\right),\left(\min V_{i j} \mid j \in J^{-}\right)\right\}=\left(V_{1}^{+}, V_{2}^{+}, \cdots, V_{m}^{+}\right) \\
V^{-}=\left\{\left(\min V_{i j} \mid j \in J^{+}\right),\left(\max V_{i j} \mid j \in J^{-}\right)\right\}=\left(V_{1}^{-}, V_{2}^{-}, \cdots, V_{m}^{-}\right)
\end{array}\right.
$$

In above formula $J^{+}$is the benefit index, $J^{-}$cost index, $m$ is the number of alternative measures.

(5) Calculating the distance between the effective alternative measures and the positive ideal solution and the negative ideal solution. $S_{i}^{+}$and $S_{i}^{-}$is the distance between the effective alternative measures and the positive ideal solution and the negative ideal solution, respectively.

$$
S_{i}^{+}=\sqrt{\sum_{j=1}^{n}\left(V_{j i}-V_{j}^{+}\right)^{2}}, S_{i}^{-}=\sqrt{\sum_{j=1}^{n}\left(V_{j i}-V_{j}^{-}\right)^{2}}, j=1,2, \cdots, n
$$

(6) Determine the relative proximity. Assuming $C_{i}$ is the relative proximity index of the preventive maintenance measure i to the ideal solution, then,

$$
C_{i}=S_{i}^{-} /\left(S_{i}^{+}+S_{i}^{-}\right)
$$

(7) Sorting relative proximity by descending order.

\section{CASE ANALYSIS}

\subsection{CASE DESCRIPTION}

A section of the highway in Jingzhou, is $5 \mathrm{~km}$ long in a one-way, two-way six lane, is fully opened to traffic on December 2011. The survey found that pavement condition of is a good, but local road section has small cracks, skid resistance performance is insufficient. Highway maintenance management department hopes to improve pavement skid resistance, pavement crack repair, maintenance costs as low as possible, while the construction period can be shorter, reduce traffic disturbances. Decision-making process in accordance with Fig. 1 , through the road condition survey, there are six alternative measures, as shown in Table 1. 
TABLE 1. Alternative preventive maintenance measures

\begin{tabular}{|c|c|c|c|c|c|}
\hline \multirow{2}{*}{$\begin{array}{l}\text { Preventive } \\
\text { technology }\end{array}$} & \multicolumn{3}{|c|}{ Analysis on the applicable conditions of decision-making measures } & \multirow{2}{*}{$\begin{array}{l}\text { Life } \\
\text { (years) }\end{array}$} & \multirow{2}{*}{$\begin{array}{c}\text { Unit } \\
\text { cost } \\
\text { (yuan) }\end{array}$} \\
\hline & pavement condition & $\begin{array}{c}\text { traffic } \\
\text { volume }\end{array}$ & Climate & & \\
\hline $\begin{array}{l}\text { (1) ultrathin wear } \\
\text { layer }\end{array}$ & $\begin{array}{l}\text { Breakage, bleeding, polishing, insufficient skid, water } \\
\text { seepage, slightly loose }\end{array}$ & all & warm & $2-4$ & $45-65$ \\
\hline $\begin{array}{l}\text { (2)crack pouring, } \\
\text { sealing }\end{array}$ & $\begin{array}{l}\text { New roadbed, insufficient bond between the surface } \\
\text { layers, cracks }\end{array}$ & $\begin{array}{l}\text { low, } \\
\text { medium }\end{array}$ & warm & $1-3$ & 3-15 \\
\hline (3) fog seal & $\begin{array}{l}\text { Turtle nets crack, reflective crack, low to moderate } \\
\text { damage }\end{array}$ & $\begin{array}{l}\text { low, } \\
\text { medium }\end{array}$ & warm & $1-2$ & $5-10$ \\
\hline (4) micro-surfacing & $\begin{array}{l}\text { Small cracks, moderate aging, insufficient slide, rutting } \\
\qquad<25 \mathrm{~mm}\end{array}$ & all & $\begin{array}{c}>10 \\
\text { degrees }\end{array}$ & $3-5$ & $18-28$ \\
\hline (5) fiber seal & $\begin{array}{l}\text { New roadbed, insufficient bond between the surface } \\
\text { layers, cracks }\end{array}$ & $\begin{array}{l}\text { low, } \\
\text { medium }\end{array}$ & warm & $1-2$ & $40-44$ \\
\hline (6) composite seal & Small cracks, moderate aging, cracks & all & warm & $1-3$ & $32-38$ \\
\hline
\end{tabular}

\subsection{PREVENTIVE MAINTENANCE DECISION INDEX SYSTEM}

According to the factors and the actual situation of preventive maintenance measures, choosing the factors that can reflect the preventive measures as the analytical index, the index system can be established from social factors, economic factors, construction factors, ecological factors, respectively. Selection of owner cost, user cost, construction period of preventive maintenance as the input index, skid resistance, durability, water resistance, driving comfort, appearance, noise reduction as the output index, four alternative preventive maintenance measures can be chose. Preventive measures indicator system of maintenance decision model is shown in Fig.2, the meaning of the measures index as shown in Tab.2.

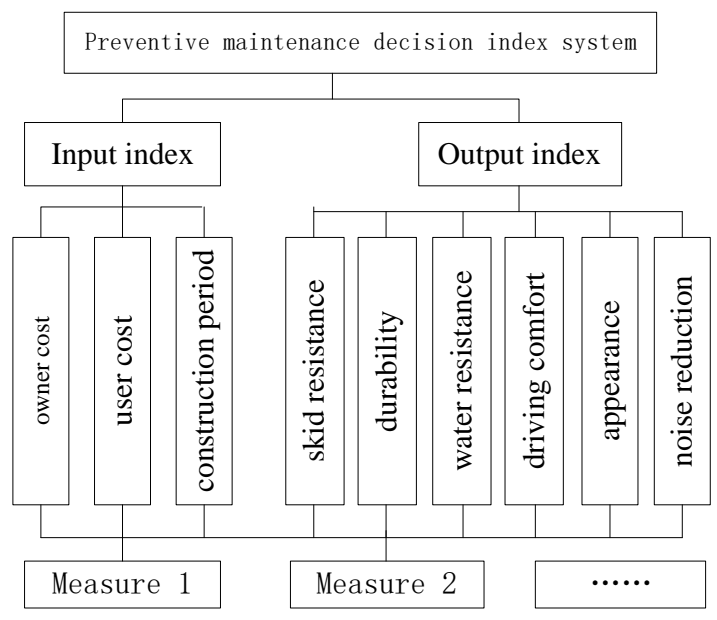

FIGURE 2 Preventive measures indicator system of maintenance decision model

TABLE2 The original data and the DEA model calculation results

\begin{tabular}{|c|c|c|c|c|c|c|c|c|c|c|}
\hline $\begin{array}{c}\text { Alternative } \\
\text { measures }\end{array}$ & $\begin{array}{c}\text { owner } \\
\text { cost } / \mathrm{km}\end{array}$ & $\begin{array}{c}\text { user cost } \\
\quad / \mathrm{km}\end{array}$ & $\begin{array}{c}\text { construction } \\
\text { period /d }\end{array}$ & $\begin{array}{c}\text { skid } \\
\text { resistance }\end{array}$ & $\begin{array}{c}\text { durability/ } \\
\text { year }\end{array}$ & $\begin{array}{c}\text { water } \\
\text { resistance }\end{array}$ & appearance & $\begin{array}{l}\text { driving } \\
\text { comfort }\end{array}$ & $\begin{array}{c}\text { noise } \\
\text { reduction }\end{array}$ & $\begin{array}{c}\text { calculation } \\
\text { results }\end{array}$ \\
\hline (1) & 40.5 & 1.5 & 7 & 5 & 5 & 4.5 & 3.5 & 5 & 4 & 1.0000 \\
\hline (3) & 10 & 1.8 & 10 & 3 & 1.5 & 4.5 & 1.5 & 3.5 & 3 & 0.8608 \\
\hline (4) & 21.5 & 1.6 & 15 & 5 & 4 & 3.5 & 4 & 5 & 3 & 1.0000 \\
\hline (6) & 10.5 & 3 & 10 & 3 & 3 & 3 & 1 & 4 & 3 & 1.0000 \\
\hline
\end{tabular}

By Table 2, the relative efficiency of the (1), (2), (4), (6) alternative is 1, however, it is impossible to define the order of them. Therefore, in the next stage, the TOPSIS method is used to sort preventive maintenance 
measures.

The matrix, which is composed by the original data in Tab.3, is called a decision matrix, and the initial standard decision matrix is obtained by the formula (2) and (3),

$$
\left(w_{1}, w_{2}, \cdots, w_{9}\right)=(0.189,0.13,0.899,0.0688,0.0566,0.1366,0.1521,0.11,0.0688)
$$

TABLE3 original data of the preventive maintenance measures

\begin{tabular}{ccccc}
\hline objective & Index name & $(1)$ & $(4)$ & (6) \\
\hline \multirow{3}{*}{ input index } & owner cost $/ \mathrm{km}$ & 40.5 & 21.5 & 10.5 \\
& user cost/km & 1.5 & 1.6 & 3 \\
& construction period/d & 7 & 15 & 10 \\
\hline \multirow{3}{*}{ output index } & skid resistance & 5 & 5 & 3 \\
& durability & 5 & 4 & 3 \\
& water resistance & 4.5 & 3.5 & 3 \\
& driving comfort & 3.5 & 4 & 1 \\
& appearance & 5 & 5 & 4 \\
\hline
\end{tabular}

The weighted normalized decision matrix can be obtained by the formula (4), and the positive and negative ideal solutions are obtained by the formula (5),

$$
\begin{aligned}
& V^{+}=(7.6545,0.39,1.3485,0.344,0.283,0.6147,0.6084,0.55,0.2752) \\
& V^{-}=(1.9845,0.195,0.6293,0.2064,0.1698,0.4098,0.1521,0.44,0.2064)
\end{aligned}
$$

According to the formula (6), (7), calculate the distance between the effective alternative measures and the $S_{i}^{+}$and $S_{i}^{-}$as well as the relative proximity index, as is shown in tab.4.

TABLE4 Calculating results

\begin{tabular}{cccc}
\hline Alternative maintenance & Positive ideal & Negative ideal solution & Relative proximity \\
measures $S_{i}$ & solution $S_{i}^{+}$ & $\left(S_{i}^{-}\right)$ & 0.8836 \\
\hline$(1)$ & 0.7490 & 5.6906 & 0.3852 \\
$(4)$ & 3.5993 & 2.2553 & 0.0550 \\
\hline
\end{tabular}

According to tab.4, ultrathin wear layer $(0.8836)>$ micro surfacing $(0.3852)>$ composite seal $(0.0550)$. Therefore, selecting ultrathin wear layer as the maintenance measures.

\section{CONCLUSION}

Road preventive maintenance decision-making is a multi-objective, multi- criteria and multi-attribute problem. When the understanding to the characteristics and decision constraints of preventive maintenance measures is not enough, selecting the appropriate measures is a more complex issue for policymakers. The paper establishes a preventive maintenance decision-making model based on DEA and TOPSIS.The model combines the advantages of DEA to solve multi-objective and multi attribute problem and the advantages of TOPSIS systemic, providing an effective way to select the appropriate preventive maintenance measures, which can guide the scientific maintenance to improve the social and economic benefits. However, there are some difficulties in quantitative analysis of some indicators, interval TOPSIS and interval DEA can be used to solve the selection of preventive maintenance measures, which is one of the research preventive maintenance measures. 


\section{ACKNOWLEDGMENTS}

The authors thank the reviewers and editors for their critical but constructive comments. The authors acknowledge the Hubei Provincial Department of Education research projects [Grant B2016548], Collaborative Research Fund from Wuhan Railway Vocational College of Technology, and Hubei Provincial Department of Education for partial financial support for this research.

\section{REFERENCES}

1.Wei, Changjun, and S. Tighe. "Development of Preventive Maintenance Decision Trees Based on Cost-Effectiveness Analysis: An Ontario Case Study." Transportation Research Record Journal of the Transportation Research Board 1866.1(2004):9-19.

2.Tsai, Yichang, Y. Wu, and E. C. Pitts. "Implementing Enhanced Georgia Department of Transportation Pavement Preservation Program."Transportation Research Board 85th Annual Meeting 2006.

3.Ravada S, Shekhar S, Lu C T, et al. Pavement Preservation Strategy Selection in California[J]. Transportation Research E-Circular, 2006, 32(1):302-308.

4.Hicks, R. G., J. Moulthrop, and J. Daleiden. "Selecting a Preventive Maintenance Treatment for Flexible Pavements." Transportation Research Record Journal of the Transportation Research Board1680.1680(2000):1-12.

5.Zeng Feng, Zhang Xiaoning. " Pavement preventive maintenance decision-making by analytic network process ". Engineering 一 Theory\&Practice.2013, 33(3):676-681

6.Nourelfath, Mustapha, N. Nahas, and M. Ben-Daya. "Integrated Preventive Maintenance and Production Decisions for Imperfect Processes." Reliability Engineering \& System Safety 148(2016):21-31.

7.Guo, Yonghe, et al. "Preventive Maintenance for Advanced Metering Infrastructure Against Malware Propagation." IEEE Transactions on Smart Grid 7.3(2016):1314-1328. 